\title{
Prognostic value of bronchoalveolar lavage in sarcoidosis: the critical influence of disease presentation
}

\author{
K WARD, C O'CONNOR, C ODLUM, M X FITZGERALD \\ From the Department of Medicine, University College Dublin, St Vincent's Hospital, Dublin
}

ABSTRACT There has been considerable disagreement about the prognostic value of broncho- $\frac{\text { ? }}{-}$ alveolar lavage lymphocyte measurements in patients with sarcoidosis. This study looks at the $c_{\stackrel{c}{ }}$ influence of the type of disease presentation and the time since onset of symptoms on lavage fluid $\stackrel{2}{5}$ lymphocyte profiles in 99 patients studied at the time of their initial diagnosis. Patients who had an acute inflammatory onset of disease with erythema nodosum $(n=32)$ or acute uveitis $(n=17) \vec{\varphi}$ almost invariably had high T lymphocyte helper : suppressor (TH : TS) ratios (mean 10.1, 95\% confidence interval 7.7-12.5) and had a higher proportion of T lymphocytes in cells obtained at lavage $(40 \%, 35-46 \%)$ than patients with a pulmonary presentation $(n=38)(\mathrm{TH}: \mathrm{TS} 2 \cdot 9,0 \cdot 2-5 \cdot 7$; T lymphocytes $21 \%, 15-27 \%)$ or those studied after resolution of erythema nodosum $(\mathrm{n}=12)$. The patients with recent erythema nodosum had the highest TH : TS ratios of any group $(10 \cdot 4,8 \cdot 1-12 \cdot 7)$. Thus lavage T lymphocyte percentage and TH : TS are highest in patients with sarcoidosis studied $\stackrel{\varnothing}{\varnothing}$ soon after an acute onset with an inflammatory condition such as erythema nodosum or uveitis. $\overrightarrow{\vec{O}}$ Patients with an acute onset of sarcoidosis have a better prognosis than those with a more insidious $\exists$ presentation. The major influence of type of disease presentation and, in the case of patients with erythema nodosum, of time since onset of symptoms may in part explain why different centres have reported such diverse results regarding the value of brochoalveolar lavage in predicting outcome in sarcoidosis. Studies where the case mix of patients includes a high proportion of patients with acute onset will not find a high TH : TS ratio or increased numbers or proportions of lavage lymphocytes to be indicators of a poor prognosis.

\section{Introduction}

Widely conflicting results have been reported from studies evaluating the utility of bronchoalveolar lavage in assessing the prognosis of patients with pulmonary sarcoidosis. Protagonists of the value of studies on lavage fluid have asserted that the intensity of the $\mathrm{T}$ lymphocyte response at the time of initial lavage in sarcoidosis has a prognostic significance. Thus in assessing the degree of alveolitis based on the proportion of $T$ lymphocytes recovered by lavage and gallium-67 scanning Keogh et $a l^{1}$ found that "the high intensity state is almost always followed by functional deterioration." Hollinger et al $^{2}$ suggested

Address for reprint requests: Dr Kevin Ward, Department of Medicine, University College Dublin, St Vincent's Hospital, Dublin 4, Ireland.

Accepted 6 October 1988 that responsiveness to steroid treatment can be predicted by analysis of the percentage of lymphocytes recovered by bronchoalveolar lavage before treat- $\frac{}{0}$ ment. Others have suggested that the ratio of lymphocyte subtypes, specifically a high helper-inducer $\mathrm{T}^{N}$ lymphocyte: suppressor-cytotoxic $T$ lymphocyte N [TH : TS) ratio, is the best lavage fluid indicator of N poor prognosis. ${ }^{34}$ In direct contrast to these con- $-\frac{\omega}{-}$ clusions are the findings of several studies that show a lack of any prognostic value of either lavage $T$. lymphocyte percentage ${ }^{5-7}$ or the TH : TS ratio. ${ }^{89}$ In the more recent publications a consensus seems to have emerged that "isolated" bronchoalveolar lavage $\overline{0}$ results are not of prognostic significance.

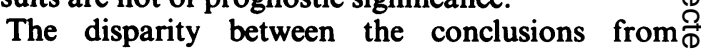
different centres is striking. Methodological variations $\varrho$ between studies might account for some of these differences. Given the great heterogeneity of sar- 
coidosis, however, the conflicting conclusions would seem more likely to arise, at least in part, from differences in the study populations. Such differences between study populations might include (1) the point in the natural history of the disease at which the study was carried out, (2) the type of disease presentation, and (3) racial and genetic differences.

The manner of presentation of pulmonary sarcoidosis may range from acute onset with erythema nodosum and bilateral hilar lymphadenopathy to chronic infiltrative pulmonary disease, where the exact time of onset may be diffcult to assess. As the time of onset of erythema nodosum is accurately known, patients with sarcoidosis presenting with erythema nodosum represent a privileged model in which to study the earliest immunological events of the disease. Valeyre et al have previously shown that the percentage of lymphocytes in lavage fluid is raised in patients with sarcoidosis and recent erythema nodosum. ${ }^{10}$

Our study set out to examine further the influence of the type and mode of presentation of sarcoidosis on lavage fluid lymphocyte numbers and subtypes. Our hypothesis was that differences in presentation and time since onset of symptoms are important factors in explaining the disagreements between investigators about the prognostic implications of lavage fluid cellular indices such as the $\mathrm{T}$ lymphocyte percentage and the TH : TS ratio.

\section{Methods}

\section{SUBJECTS}

The study group comprised 99 patients, all white, with recently diagnosed sarcoidosis. All investigations and follow up examinations were carried out at one centre, St Vincent's Hospital. No patient received systemic corticosteroid treatment before bronchoalveolar lavage.

The diagnosis of sarcoidosis was based on a combination of (1) the clinical history and the radiological findings, (2) the presence of non-caseating epithelioid cell granulomas in biopsy material, and (3) the exclusion of infectious disease, extrinsic allergic alveolitis, and exposure to inorganic material that could induce granulomas. In most cases the biopsy material was obtained at mediastinoscopy $(n=57)$; 20 patients had a positive Kveim test response and in the remainder the histological appearance of tissue obtained from palpable lymph nodes, skin, or transbronchial lung biopsy specimens was consistent with sarcoidosis. Radiological evaluation included the Siltzbach staging procedure ${ }^{11}$ (stage 0 -normal chest radiograph; stage 1 -bilateral hilar lymphadenopathy; stage 2-lymphadenopathy and pulmonary infiltration; stage 3-pulmonary infiltration without adenopathy.
The control group consisted of 14 subjects-eight healthy volunteers and six patients with normal chest radiographs who had undergone diagnostic bronchoscopy and who had had a normal chest radiograph and lung function for one year.

Patients with sarcoidosis were divided into the following groups on the basis of their clinical presentation:

Acute erythema nodosum $(\mathrm{n}=32)$ : patients who presented with acute erythema nodosum and who had bronchoalveolar lavage performed within two months of the development of acute lesions (stage 0 - one patient, stage $1-17$ patients, stage $2-13$ patients, stage 3-one patient; 21 non-smokers and 11 smokers).

Old erythema nodosum $(\mathrm{n}=12)$ : patients who had presented initially with erythema nodosum and who had lavage from two to six months from resolution of the skin lesions (stage 0 - one patient, stage 1 -nine patients, stage 2-two patients; eight non-smokers and four smokers).

Uveitis $(\mathrm{n}=17)$ : patients presenting with acute uveitis (stage 1 -four patients, stage $2-10$ patients, stage 3-three patients; 11 non-smokers and six smokers).

Respiratory symptoms $(\mathrm{n}=24)$ : patients presenting primarily with respiratory symptoms and having bronchoalveolar lavage at the time of this initial diagnosis of sarcoidosis (stage 1 -three patients, stage 2 -eight patients, stage 3-13 patients; 14 non-smokers and 10 smokers).

Asymptomatic disease with abnormal chest radiograph $(\mathrm{n}=14)$ : patients who were entirely symptomless and who were diagnosed when a routine chest radiograph was found to be abnormal, lavage again being performed at the time of diagnosis; 14 patients; stage 1-four patients, stage 2-six patients, stage 3-four patients; nine non-smokers and five smokers.

BRONCHOALVEOLAR LAVAGE

Bronchoalveolar lavage was performed during fibreoptic bronchoscopy under local anaesthesia. Premedication with atropine and pethidine was routinely used. Patients were further sedated with 5$10 \mathrm{mg}$ of parenterally administered diazepam as required. The lavage was performed in a segmental or subsegmental right middle lobe bronchus. Before the lavage the bronchus was anaesthetised with $2 \mathrm{ml}$ of $1 \%$ lignocaine hydrochloride. The bronchoscope was wedged in a subsegment and $180 \mathrm{ml}$ of normal saline was instilled in three $60 \mathrm{ml}$ aliquots. The mean volume of fluid recovered was 94 (SD 27) $\mathrm{ml}$ after it had been filtered to remove mucus. The lavage fluid was centrifuged at $500 \mathrm{~g}$ for five minutes to recover cells.

LAVAGE FLUID CELLULAR ANALYSIS

The recovered cells were washed twice in Hanks's 
balanced salt solution and resuspended in RPMI 1640. The total cell count and the number of cells $/ \mathrm{ml}$ of lavage fluid were obtained by using an Improved Neubauer counting chamber. Differential counts were made by using a modified Giesma stain (Diff-Quik, American Hospital Supply Company, Didcot). The cells were then adjusted to a concentration of $2 \times 10^{6}$ cells $/ \mathrm{ml}$ and analysed in terms of type. Analyses of $\mathrm{T}$ lymphocytes and $\mathrm{T}$ lymphocyte subsets were performed with monoclonal antibodies of the Leu series (Becton Dickinson, Mechelen, Belgium) ${ }^{12}$ as follows: total lymphocyte count-anti-Leu 1; suppressorcytotoxic $T$ cells-anti-Leu $2 \mathrm{a}$; helper-inducer $\mathrm{T}$ cells-anti-Leu $3 \mathrm{a}$. In each case at least 300 cells were counted to obtain an accurate count. The correlation coefficient ( $r$ ) between the Diff-Quik lymphocyte count and the cells identified with the anti-Leu 1 antibody was 0.77 . Cell viability was measured by the ethidium bromide-acridine orange fluorescence method (Becton Dickinson, Mechelen, Belgium). ${ }^{13}$

\section{STA TISTICAL ANAL YSES}

Statistical analyses were performed with Statgraphics (Statistical Graphics Corporation, Rockville, Maryland, USA), a statistical software package for use with IBM personal computers. Between group comparisons were performed by analysis of variance. Within group comparisons were made by means of the two sample $t$ test with Bonferroni's modification for multiple $t$ tests. As six groups were being compared a two sample $t$ test p value of $<0.0033$ was considered significant at the $5 \%$ level and a p value of $<0.0007$ at the $1 \%$ level. Comparisons between the pooled results of the patients with acute and with non-acute presentations were made with the two sample $t$ test.

\section{Results}

\section{GENERAL FEATURES OF THE LAVAGE FLUID}

Table 1 shows age, volume of lavage fluid recovered, total number of cells recovered, and cell viability for each group of patients. The mean ages and the age ranges of the different groups were broadly the same with one exception: the patients in the group with acute erythema nodosum (mean age 28 years) were younger than the patients in the group with respiratory symptoms (mean age 37 years; $p<0.01$ ) and the symptomless patients with abnormal chest radiographs (mean age $36 ; \mathrm{p}<0.05$ ). The largest lavage fluid recovery was from the group with acute uveitis (mean $105 \mathrm{ml}$ ) and the lowest for the group with respiratory symptoms (mean $83 \mathrm{ml}$ ), but there were no significant intergroup differences. The total number of cells recovered did not differ significantly between the groups of patients. The cell viability was significantly lower in the group with respiratory symptoms than in either of the erythema nodosum groups or the symptomless group $(p<0.05)$.

\section{DISEASE PRESENTATION AND LAVAGE}

LYMPHOCYTE PROFILES

The most notable differences in lavage cellular profiles between the various groups are summarised in table $2 \vec{\bullet}$ and detailed diagrammatically in figures 1 and 2 . The striking finding is that the two groups presenting with acute inflammatory events-acute erythema nodosum or uveitis-had higher lavage $\mathrm{T}$ lymphocyte percentages (fig 1), TH cell percentages and TH : TS ratios (fig 2) than the other groups with sarcoidosis and the controls $(p<0.01)$. There was no significant difference between the control group and the other three sarcoid groups in respect of $\mathrm{T}$ lymphocytes $\%$, TH cells \%, or TH : TS ratio. Although these groups of patients showed no significant differences from the control group some patients initially presenting with respiratory symptoms or with an asymptomatic radiological abnormality had a high percentage of $T$ lymphocytes and TH cells and high TH : TS ratios; this phenomenon was not observed in any subjects in the control group. There was no difference between any of the six groups in the percentages of TS cells.

Table 2 also shows the results of comparing an acute inflammatory onset group (acute erythema nodosum and uveitis groups combined) with a non-acute inflam-

Table 1 Age, lavage fluid volume, total number of cells, and cell viability for patients in each disease presentation category (means with $95 \%$ confidence limits)

\begin{tabular}{|c|c|c|c|c|c|}
\hline & & $\begin{array}{l}\text { Age } \\
(y)\end{array}$ & $\begin{array}{l}\text { BAL volume } \\
(\mathrm{ml})\end{array}$ & $\begin{array}{l}\text { Total No of } \\
\text { cells }(\times 10)\end{array}$ & $\begin{array}{l}\text { Cell viability } \\
(\%)\end{array}$ \\
\hline $\begin{array}{l}\text { Acute erythema nodosum }(n=32) \\
\text { Old erythema nodosum }(n=12) \\
\text { Uveitis }(n=17) \\
\text { Respiratory }(n=24) \\
\text { Radiographic symptomless }(n=14) \\
\text { Control }(n=14)\end{array}$ & & $\begin{array}{l}28 \cdot 1(24-32) \\
30 \cdot 9(25-37) \\
31 \cdot 6(26-37) \\
37 \cdot 1(33-41) \\
36 \cdot 4(31-42) \\
27 \cdot 2(24-32)\end{array}$ & $\begin{array}{c}92(83-101) \\
102(87-118) \\
105(92-118) \\
83(72-94) \\
92(78-106) \\
105(93-118)\end{array}$ & $\begin{array}{l}23 \cdot 5(15 \cdot 5-31 \cdot 6) \\
25 \cdot 4(12 \cdot 2-38 \cdot 5) \\
28 \cdot 2(17 \cdot 1-39 \cdot 2) \\
24 \cdot 5(15 \cdot 2-33 \cdot 8) \\
16 \cdot 4(4 \cdot 7-28 \cdot 2) \\
19 \cdot 4(8 \cdot 3-30 \cdot 4)\end{array}$ & $\begin{array}{l}84.9(79-90) \\
86 \cdot 1(79-93) \\
80 \cdot 4(73-88) \\
71 \cdot 7(66-78) \\
85 \cdot 8(79-93) \\
81 \cdot 5(75-88)\end{array}$ \\
\hline $\begin{array}{l}\text { Analysis of variance } \\
\text { (sarcoid groups only) }\end{array}$ & p: & 0.025 & 0.087 & 0.68 & 0.014 \\
\hline \multicolumn{6}{|l|}{ BAL_lavage fluid. } \\
\hline
\end{tabular}


Table $2 T$ lymphocytes and $T$ lymphocyte subpopulations (percentages of total cells) for patients in each disease presentation category (means with $95 \%$ confidence limits)

\begin{tabular}{|c|c|c|c|c|c|}
\hline & & $\begin{array}{l}\text { Leu la } \\
\text { (Tlymphocytes) } \\
(\%)\end{array}$ & $\begin{array}{l}\text { Leu } 3 a \\
\text { (Thelpers) } \\
(\%)\end{array}$ & $\begin{array}{l}\text { Leu } 2 a \\
\text { (T suppressors) } \\
(\%)\end{array}$ & $\begin{array}{l}\text { Leu 3a:Leu } 2 a \\
\text { (TH:TS } \\
\text { ratio) }\end{array}$ \\
\hline $\begin{array}{l}\text { Acute erythema nodosum }(n=32) \\
\text { Old erythema nodosum }(n=12) \\
\text { Uveitis }(n=17) \\
\text { Respiratory }(n=24) \\
\text { Radiographic symptomless }(n=14) \\
\text { Control }(n=14)\end{array}$ & & $\begin{array}{l}39(32-45) \\
14(3-24) \\
43(35-52) \\
19(11-26) \\
25(15-35) \\
10(1-18)\end{array}$ & $\begin{array}{l}33(28-39) \\
9(0-18) \\
37(29-44) \\
13(7-19) \\
18(10-27) \\
5(-3-12)\end{array}$ & $\begin{array}{l}5(3-6) \\
6(3-9) \\
6(3-8) \\
6(4-8) \\
6(4-9) \\
6(4-8)\end{array}$ & $\begin{array}{l}10 \cdot 4(8 \cdot 1-12 \cdot 7) \\
1 \cdot 3(-2 \cdot 5-5 \cdot 1) \\
7 \cdot 3(4 \cdot 1-10 \cdot 5) \\
2 \cdot 3(-0 \cdot 4-5 \cdot 0) \\
3 \cdot 9(0 \cdot 4-7 \cdot 4) \\
1 \cdot 2(-2 \cdot 2-4 \cdot 5)\end{array}$ \\
\hline $\begin{array}{l}\text { Analysis of variance } \\
\text { (sarcoid groups only) }\end{array}$ & $\mathrm{p}:$ & 0.0001 & 0.0001 & 0.83 & 0.0001 \\
\hline $\begin{array}{l}\text { Acute onset } \\
\text { (acute EN or uveitis) }\end{array}$ & & $40(35-46)$ & $34(29-39)$ & $6(5-8)$ & $10 \cdot 1(7 \cdot 7-12 \cdot 5)$ \\
\hline $\begin{array}{l}\text { Other onset } \\
\text { (respiratory or radiographic } \\
\text { symptomless) }\end{array}$ & & $21(15-27)$ & $15(9-21)$ & $5(4-6)$ & $2 \cdot 9(0.2-5 \cdot 7)$ \\
\hline $\begin{array}{l}\text { Two sample } t \text { test } \\
\text { (acute onset } v \text { other) }\end{array}$ & p: & 0.0004 & 0.0001 & 0.41 & 0.0001 \\
\hline
\end{tabular}

matory group (respiratory symptoms and symptomless groups). The acute onset group had higher percentages of lavage $T$ lymphocytes $(p<0.001)$ and T helper cells $(p<0.001)$ and a higher TH : TS ratio $(\mathrm{p}<0.001)$.

\section{TIME SINCE ONSET OF SYMPTOMS}

The differences in $T$ lymphocyte percentage and TH : TS ratios as a function of time since first onset of erythema nodosum is shown in figures 3 and 4 . There seems to be a progressive diminution over time in lavage T lymphocyte percentage and TH : TS ratio for erythema nodosum patients (correlation coefficients (r): $\mathrm{T}$ lymphocyte $\% \mathrm{r}=-0.38(\mathrm{p}=0.013) ; \mathrm{TH}$ : TS $r=-0.31(p=0.048)$. This downward trend from high to normal lymphocyte counts with time is not seen with the patients with uveitis or respiratory symptoms ( $T$ lymphocyte $\% \mathrm{r}=-0.13$ and $\mathrm{r}=$ -0.03 ). Unfortunately this type of analysis is confounded by the difficulties of assessing the time of onset of respiratory symptoms and the unpredictable time course of uveitis in many patients.

\section{RADIOLOGICAL STAGE AND LAVAGE RESULTS}

The relation between radiological stage and cellular profiles in the two acute inflammatory groups (acute erythema nodosum and uveitis) and the groups presenting with symptomless radiographic abnormality and with the respiratory symptoms is illustrated in the cross tabulation tables (tables 3 and 4). There was no significant difference in $T$ lymphocyte percentage or the TH : TS ratio in patients with the same

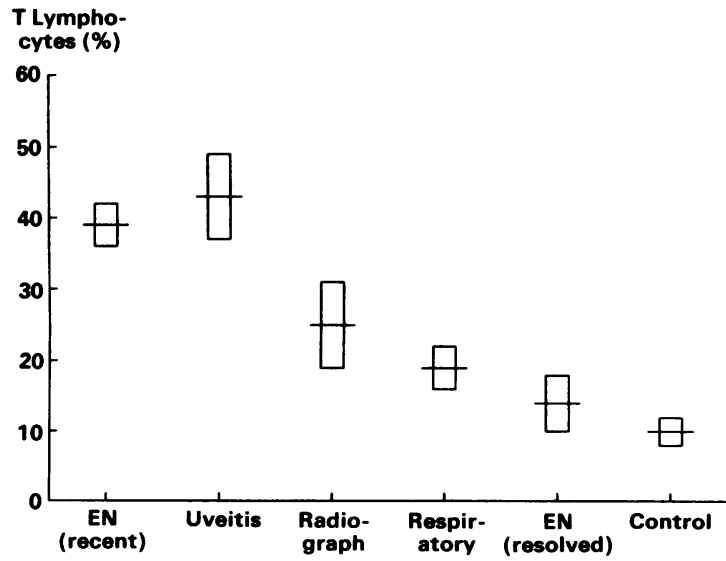

Fig 1 Percentage of $T$ lymphocytes in lavage fluid for each disease presentation category (means with standard errors).

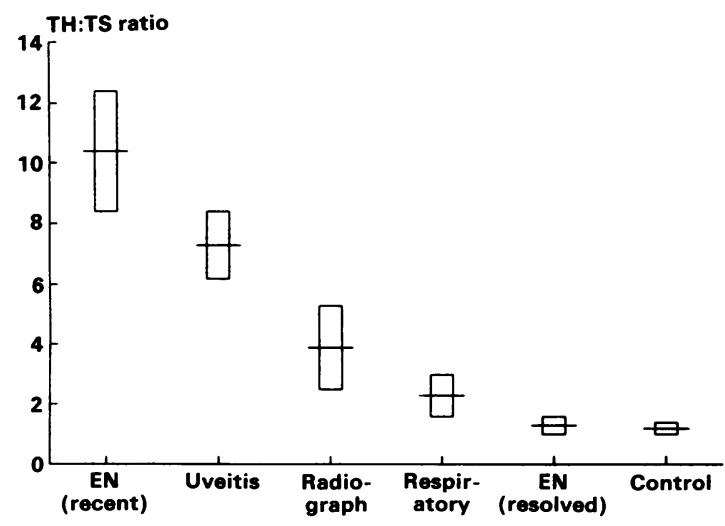

Fig 2 Leu $3 a$ : Leu $2 a$ ratio (TH: TS ratio) in lavage fluid for each disease presentation category (means with standard errors). 


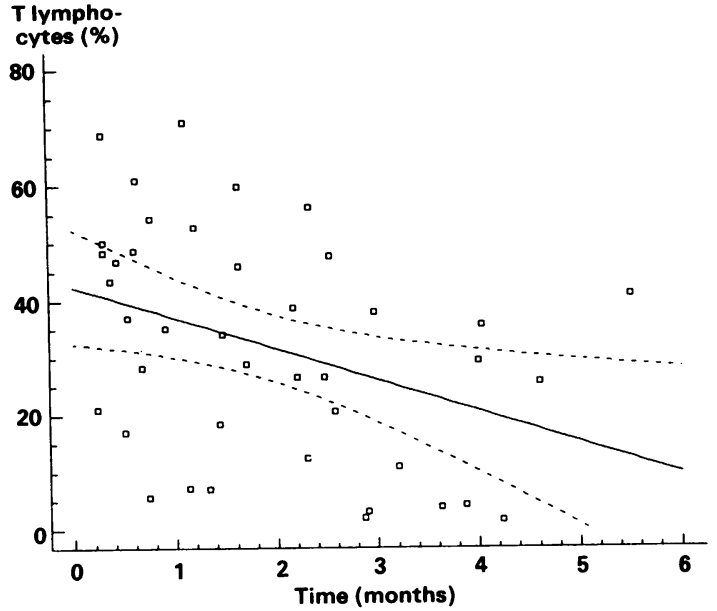

Fig 3 Percentage of $T$ lymphocytes in lavage fluid in relation to time (months) since the onset of erythema nodosum: linear regression line with $95 \%$ confidence limits.

disease presentation but different radiographic stages of disease, with one exception. Patients with recent erythema nodosum who had stage 1 disease had a greater $T$ lymphocyte percentage count than those who had stage 2 disease $(p<0.05)$. No relationship between radiographic stage and cellular profiles was observed in the respiratory symptoms group or the symptomless group. Thus disease presentation and the time between the onset of symptoms and study appear to influence lavage lymphocyte profiles more strongly than chest radiographic stage.

\section{PULMONARY FUNCTION AND PROGNOSIS}

Patients presenting with respiratory symptoms had, predictably, significantly lower FVC and carbon monoxide transfer (TLCO) values than any other group
TH:TS ratio

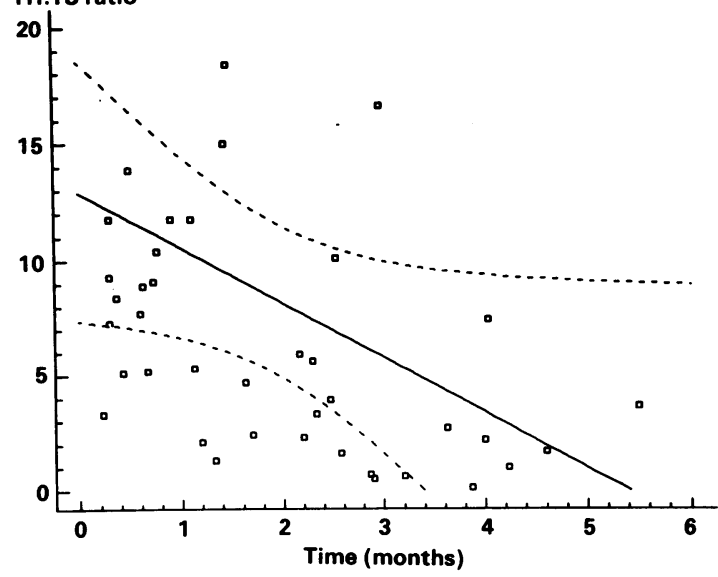

Fig 4 Leu $3 a:$ Leu 2 a ratio (TH:TS ratio) in lavage fluid in relation to time (months) since the onset of erythema nodosum: linear regression line with $95 \%$ confidence limits.

( $\mathrm{p}<0.05$ ). The initial FVC \% predicted (mean, $95 \%$ confidence limits) for the various groups was as follows: respiratory 78 (70-84), uveitis 92 (83-100), symptomless 94 (84-104), and erythema nodosum 98 (91-104). Initial values for gas transfer for each group were very similar when expressed as $\%$ predicted to the FVC values.

There was a mean improvement in pulmonary function in all patient groups during follow up (mean 22 months). Only the erythema nodosum group, however, showed significant spontaneous improvement. Untreated patients with erythema nodosum $(\mathrm{n}=29)$ improved their FVC $\%$ predicted by $7 \%(3 \cdot 2-10 \cdot 2)$ while untreated respiratory patients $(n=12)$ showed no significant improvement ( $p<0.001$ for difference between change in FVC in erythema nodosum group $v$ respiratory group).

Table 3 Cross tabulation of T lymphocyte percentages (mean (95\% confidence limits)) for chest radiographic stages and disease presentation categories (results shown for groups of three or more patients)

\begin{tabular}{|c|c|c|c|c|}
\hline \multirow[b]{2}{*}{ Presentation } & \multicolumn{3}{|c|}{ Chest radiograph } & \multirow[b]{2}{*}{ All } \\
\hline & Stage 1 & Stage 2 & Stage 3 & \\
\hline Recent erythema nodosum & $\begin{array}{l}43(34: 52) \\
n=17\end{array}$ & $\begin{array}{l}29(18: 40) \\
n=13\end{array}$ & \multirow{5}{*}{$\begin{array}{l}31(12: 51) \\
n=3 \\
19(2: 36) \\
n=4 \\
17(8: 26) \\
n=13 \\
25(18: 32)\end{array}$} & $39(32: 45)$ \\
\hline Uveitis & $\begin{array}{l}35(16: 54) \\
n=4\end{array}$ & $\begin{array}{l}50(38: 63) \\
n=10\end{array}$ & & $43(35: 53)$ \\
\hline Radiographic symptomless & $\begin{array}{l}20(2: 39) \\
n=4\end{array}$ & $\begin{array}{l}32(16: 48) \\
n=6\end{array}$ & & $25(15: 35)$ \\
\hline Respiratory & $\begin{array}{l}23(1: 45) \\
n=3\end{array}$ & $\begin{array}{l}20(6: 34) \\
n=8\end{array}$ & & $19(11: 26)$ \\
\hline All & $32(26: 37)$ & $32(26: 38)$ & & \\
\hline
\end{tabular}

Control group values: mean $10 \%, 95 \%$ confidence limits $1-19 \%$. 
Table 4 Cross tabulation of Leu 3a:Leu 2a ratios (TH:TS ratios) in lavage fluid (mean (95\% confidence limits)) for chest radiographic stages and disease presentation categories (results shown for groups of three or more patients)

\begin{tabular}{|c|c|c|c|c|}
\hline \multirow[b]{2}{*}{ Presentation } & \multicolumn{3}{|l|}{ Chest radiograph } & \multirow[b]{2}{*}{ All } \\
\hline & Stage 1 & Stage 2 & Stage 3 & \\
\hline Recent erythema nodosum & $\begin{array}{l}10 \cdot 9(6 \cdot 7: 15 \cdot 1) \\
n=17\end{array}$ & $\begin{array}{l}10 \cdot 8(6 \cdot 6: 15 \cdot 1) \\
n=13\end{array}$ & & $10 \cdot 4(8 \cdot 1: 12 \cdot 7)$ \\
\hline Uveitis & $\begin{array}{l}7 \cdot 7(-0.9: 16 \cdot 4) \\
n=4\end{array}$ & $\begin{array}{l}7 \cdot 4(2 \cdot 6: 12 \cdot 2) \\
n=10\end{array}$ & $\begin{array}{l}6 \cdot 3(1 \cdot 0: 11 \cdot 5) \\
n=3\end{array}$ & $7 \cdot 3(4 \cdot 1: 10 \cdot 5)$ \\
\hline Radiographic symptomless & $\begin{array}{c}2 \cdot 2(-6 \cdot 5: 10 \cdot 8) \\
n=4\end{array}$ & $\underset{n=6}{3 \cdot 8}(-2 \cdot 4: 10 \cdot 1)$ & $\begin{array}{l}5 \cdot 7(1 \cdot 1: 10 \cdot 2) \\
n=4\end{array}$ & $3.9(0.4: 7 \cdot 4)$ \\
\hline Respiratory & $\begin{array}{l}2 \cdot 4(-7 \cdot 6: 12 \cdot 5) \\
n=3\end{array}$ & $\begin{array}{l}4 \cdot 0(-1 \cdot 4: 9 \cdot 4) \\
n=8\end{array}$ & $\begin{array}{l}1 \cdot 3(-1 \cdot 3: 3 \cdot 8) \\
n=13\end{array}$ & $2 \cdot 3(-0 \cdot 4: 5 \cdot 0)$ \\
\hline All & $6 \cdot 3(3 \cdot 6: 8 \cdot 9)$ & $6 \cdot 6(4 \cdot 4: 8 \cdot 8)$ & $2 \cdot 9(1 \cdot 0: 4 \cdot 8)$ & \\
\hline
\end{tabular}

Control group values: mean $1 \cdot 2,95 \%$ confidence limits $-2 \cdot 2-4 \cdot 5$.

\section{Discussion}

The most striking findings in this study are the very high TH : TS ratio and the high percentage lymphocyte count in the lavage fluid of patients with sarcoidosis presenting with an acute onset such as erythema nodosum or uveitis. We cannot be certain whether this intense alveolitis is a reflection of some factor associated with the clinical presentation or whether it is related to the early point in time when the disease was studied. Our data show that the alveolitis of patients with erythema nodosum is related predictably to the time of presentation. Patients in the other disease presentation categories showed no time related differences in the percentage of lymphocytes or the TH : TS ratio in lavage fluid. Direct comparison between groups of patients is probably invalid as estimating the exact time of onset of respiratory symptoms, for example, is much more difficult than assessing the time of onset of erythema nodosum. Furthermore, the activity over time of both uveitis and respiratory symptoms, which often pursue a relapsing course, is much less predictable than that of erythema nodosum, which usually resolves quickly. For patients with erythema nodosum the intensity of the lymphocyte response is largely dependent on the time since onset of the disease, although we cannot rule out the influence of some factor specific to the mode of clinical presentation. Finally, chest radiographic stage, assessed by the Siltzbach classification, was not an independent influence on the results of lavage lymphocyte analyses.

It has been suggested that a "high intensity alveolitis," indicated chiefly by a high percentage lymphocyte count in the lavage fluid, presages progressive disease and dictates the necessity for steroid treatment. ${ }^{14}$ Erythema nodosum is a presentation of sarcoidosis generally recognised as heralding the most benign form of the disease ${ }^{15}$; this observation was confirmed by the very significant spontaneous improvement in our untreated patients with erythema nodosum. The apparent contradiction between the studies that have found lymphocytosis of the lavage fluid to be a prognostic indicator and this present report is best explained on the basis of differences in the case mix of the populations in the various studies. Clearly any study such as ours that includes a high proportion of patients with an acute inflammatory onset will not find that either increased lymphocyte numbers or an increase in lavage lymphocyte percentage or an increase in the TH : TS ratio correlate with a poor prognosis.

Our data do not explain all of the conflicting conclusions of other studies. Methodological differences in lavage protocols have also been shown to influence cell yields and differential counts; the site of lavage, the volume of saline instilled, the choice of aliquot sampled, and the type of specimen concentration used may all influence the results obtained. ${ }^{1617}$ Furthermore, racial and genetic differences between study groups will influence the conclusions reached. ${ }^{18}$

Even when very similar groups are compared some differences may still be encountered. The original observation of a high percentage of lavage lymphocytes in patients with sarcoidosis who have erythema nodosum was made in 14 patients described by Valeyre et $a l^{10}$ but there are differences between the results of that study and the present report. Valeyre and colleagues found that lavage lymphocyte percentage increased during the first eight weeks after onset of erythema nodosum; in striking contrast, we found a fairly predictable steady decline in lavage lymphocyte percentage after the onset of erythema nodosum. Additionally, there are inexplicable differences in pulmonary function between their patients and ours; 12 of their patients had a carbon monoxide transfer factor (TLCO) value of less than $80 \%$ predicted; our patients with erythema nodosum almost invariably were normal both in TLCO and in other pulmonary function indices. 
There is now a consensus that while cellular analyses of lavage fluid have provided valuable information on the mechanism of disease progression in sarcoidosis their usefulness as accurate prognostic indicators is becoming increasingly questionable. Our study clearly shows that the category of disease presentation and the time since onset of symptoms are of crucial importance to the interpretation of individual lavage results. Any future study designed to assess the prognostic value of lavage cellular analysis in sarcoidosis should ideally use a standardised methodological protocol and stratify patients according to race and both the mode and the time profile of clinical presentation. This approach would be difficult, but if it were successful the results of lavage lymphocyte analyses might have a prognostic significance that they do not have at present.

We wish to thank Dr W McNicholas for permission to study patients under his care. This study was supported by a grant from the Medical Research Council of Ireland.

\section{References}

1 Keogh BA, Hunninghake GW, Line BR,Crystal RG. The alveolitis of pulmonary sarcoidosis. Am Rev Respir Dis 1983;128:256-65.

2 Hollinger WM, Staton GW, Fajman WA, Gilman MJ, Pine JR, Check IJ. Prediction of therapeutic response in steroid-treated pulmonary sarcoidosis. Evaluation of clinical parameters, bronchoalveolar lavage, gallium-67 scanning, and serum angiotensin-converting enzyme levels Am Rev Respir Dis 1985;132:65-9.

3 Costabel U, Bross KJ, Guzman J, Nilles A, Ruhle KH, Matthys H. Predictive value of bronchoalveolar lavage $\mathrm{T}$ cell subsets for the course of pulmonary sarcoidosis. Ann NY Acad Sci 1986;465:418-26.

4 Baughmann RP, Fernandez M, Bosken CH, Mantil J, Hurtubise P. Comparison of gallium-67 scanning, bronchoalveolar lavage, and serum angiotensin-converting enzyme levels in pulmonary sarcoidosis. Am Rev Respir Dis 1984;129:676-81.

5 Buchalter S, Jackson WAL, Chandler D, Jackson R, Fulmer J. Bronchoalveolar lavage cell analysis in sarcoidosis; a comparison of lymphocyte counts and clinical course. Ann NY Acad Sci 1986;465:678-84.

6 Turner-Warwick M, McAllister W, Lawrence R, Britten $\mathscr{\overline { G }}$ A, Haslam PL. Corticosteroid treatment in pulmonary sarcoidosis: do serial lavage lymphocyte counts, serum $\bar{\sigma}$ angiotensin converting enzyme measurements, and $\bar{s}$ gallium-67 scans help management? Thorax 1986; 41:903-13.

7 Delaval P, Pencole C, Bourguet P, et al. Predictive value of serum angiotensin converting enzyme, broncho- $\overrightarrow{0}$ alveolar lavage $\mathrm{T}$ lymphocyte subsets and gallium-67 lung scan in pulmonary sarcoidosis [abstract]. Sarcoidosis 1986;3:177.

8 Greening AP, Nunn P, Dobson N, Rudolf M, Rees ADM. Pulmonary sarcoidosis: alterations in bronchoalveolar lavage lymphocytes and $\mathrm{T}$ cell subsets. Thorax 1985;40:278-83.

9 Taskinen E, Tukiainen P, Riska H, Wangel A. Relationship between the differential cell count and lymphocyte subsets of BAL and the clinical findings in sarcoidosis [abstract]. Sarcoidosis 1986;3:183.

10 Valeyre D, Saumon G, Georges R, et al. The relationship between disease duration and noninvasive pulmonary explorations in sarcoidosis with erythema nodosum. Am Rev Respir Dis 1984;129:938-43.

11 Siltzbach LE. Sarcoidosis: clinical features and management. Med Clin North Am 1967;51:483-502.

12 Evans RL, Wall DW, Platsoucas CD, et al. Thymusdependent membrane antigens in man: inhibition of cell-mediated lympholysis by monoclonal antibodies to the $\mathrm{T}_{\mathrm{H} 2}$ antigen. Proc Natl Acad Sci 1981;78:544-8.

13 Parks DR, Bryan VM, Oi VM, Oi VT, Hervenberg LA. ® Antigen specific identification and cloning of $\overrightarrow{\vec{D}}$ hybridomas with a fluorescence activated cell sorter 3 (FACS). Proc Natl Acad Sci 1979;76:1962-8.

14 Keogh BA, Crystal RG. Alveolitis: the key to the interstitial lung disorders. Thorax 1982;37:1-10.

15 Scadding JG, Mitchell DN. Sarcoidosis. London: Chapman and Hall, 1985:94-6.

16 Garcia JGN, Wolven RG, Garcia P, Keogh BA. Assessment of interlobar variation of bronchoalveolar lavage cellular differentials in interstitial lung diseases. $A m$ Rev Respir Dis 1986;133:444-9.

17 Cole P, Turton C, Laydon H, Collins J. Bronchoalveolar lavage for the preparation of free lung cells, techniques $\mathrm{O}$ and complications. Br J Dis Chest 1980;74:273-8.

18 Israel HI, Karlin P, Menduke $H$. Factors affecting outcome of sarcoidosis: influence of race, extrathoracic involvement and initial radiologic lung lesions. Ann NY $\mathrm{N}$ Acad Sci 1986;465:609-18. 